\title{
NOVAS LIDERANÇAS SUL-AMERICANAS: CLIVAGENS SOBRE O BINÔMIO ESTABILIDADE-INSTABILIDADE POLÍTICA
}

\author{
Rafael Duarte Villa
}

\begin{abstract}
RESUMO
Este artigo trata da instabilidade política na América Latina, especialmente dos países componentes da Região Andina, do Cone Sul e do Brasil. Investigamos as causas do surgimento de novas lideranças políticas nesses países e a relação dessas lideranças com situações de estabilidade ou de instabilidade políticas. $O$ artigo sustenta que o surgimento de novas lideranças na América Latina, que tem emergido numa dinâmica de estabilidade e instabilidade política, não pode ser compreendido unicamente por hipóteses que ressaltem os traços populistas ou de falhas da modernização política, dado que a casuística mais profunda de tal emergência deveria ser procurada em novas clivagens que apontam para uma renovação de elites, mas também para o surgimento de clivagens de identidade étnica e social assim como de um novo padrão de relacionamento entre movimentos sociais e novas lideranças. Concluímos que a ascensão de novas lideranças políticas nos países analisados está geralmente ligada a uma crise de legitimidade do sistema político. Assumimos também que o "neopopulismo" pode ser uma variável explicativa da emergência de novos atores nos contextos de instabilidade política, não podendo tal variável, entretanto, ser descontextualizada.
\end{abstract}

PALAVRAS-CHAVE: elite política; neopopulismo; Região Andina; instabilidade política; legitimidade política; economicismo.

\section{INTRODUÇÃO}

A instabilidade política na região dos Andes tem chamado a atenção pela sua instabilidade ainda que a região do Cone Sul mais o Brasil (se excetuamos o Paraguai) tenda a apresentar mais estabilidade do ponto de vista político. Não há espaço, então, para adiantar hipóteses sobre qual das situações é mais intensa. Mas cabem algumas percepções em comum sobre a região como um todo. A América do Sul apresenta uma mistura de desigualdade, pobreza, violência e desemprego. A América Latina começou o novo milênio com uma parcela de $45 \%$ de sua população ganhando até dois dólares por dia, e sendo um dos continentes mais violentos do mundo. Conhecer alguns lugares como o Sul do Brasil é como pensar que estamos num lugar que não deve nada aos paises de modernização avançada. No entanto, essa percepção desfaz-se quando percebemos que as regiões Norte e Nordeste do país são economicamente atrasadas e socialmente muito desiguais. Mesmo quando pensamos em países como a Bolívia, não parece estranho que o país divida-se entre uma região alta de imensa desigualdade social e uma região oriental de muito dinamismo econômico, que conta com um agronegócio bastante moderno.

Em princípio, poderia ser possível atribuir essas assimetrias à incapacidade dos operadores tradicionais da política, sejam eles partidos ou lideranças, em completar um processo de modernização bem-sucedido. A modernização nesses países seria incompleta porque não se conseguiu resolver com suficiente eficácia a promessa de reforma agrária ou a promessa da industrialização por meio da substituição de importações. A promessa da reforma agrária a milhões de pessoas carentes foi sempre uma invariante na América Latina. Foi também a grande promessa da Revolução Mexicana e a promessa dos governos democráticos e autoritários que se instalaram na América Latina desde os anos 1950 e 1960. No início do terceiro milênio constata-se que a reforma agrária, uma das principais promessas dos governos nacionalistas e reformistas dos anos 1960, pouco materializouse em fatos. Na verdade, a história parece ter agido em sentido inverso. Em vez de uma partilha justa e eqüitativa da terra, deparamos-nos com uma alta concentração da terra em mãos de setores latifundiários. 
Quanto ao segundo aspecto, a industrialização, é importante lembrar que nos anos 19850 e 1960 havia uma fé quase mística em que a solução para o problema de nosso desenvolvimento político e social era a industrialização. Esse pensamento foi firmemente representado pela Comissão Econômica para a América Latina (Cepal). Partiase da seguinte hipótese economicista: a América Latina era subdesenvolvida política e socialmente porque era subdesenvolvida economicamente. Então, a industrialização aparecia como o carrochefe da modernidade que os latino-americanos ainda não haviam atingido. Ao mesmo tempo, esse processo deveria ser dirigido pelo Estado, tendo como companheiro a burguesia nacional.

É notável que, apesar de que tal foi uma promessa não cumprida, América Latina conseguiu crescer a taxas de $7 \%$ ao ano. Porém, crescimento não significou industrialização. $\mathrm{O}$ resultado foi que a América Latina chegou às décadas de 1980 e 1990 não industrializada, mas endividada, com altas taxas de desemprego, inflação; aumento dos níveis de pobreza e com a diminuição do crescimento do produto interno bruto (PIB). Essas décadas certamente foram “décadas perdidas”. Para tanto, não é de estranhar que, hoje, na América Latina, quase metade da população viva abaixo da linha da pobreza, isto é, vivendo com menos de dois dólares por dia.

A modernização incompleta é uma variável altamente sedutora para explicar por que setores menos organizados encontram incentivos para apoiar a mudança. Mas essa variável sociológica, embora importante para explicar o desejo de mudança política no curto prazo de amplos setores das populações sul-americanas, não é suficiente para explicar a estabilidade ou instabilidade política, ou a razão de a estabilidade política coexistir com a estabilidade política ou com a continuidade política no médio e longo prazo.

\section{SEIS CLIVAGENS NA BASE DA ESTABILIDADE E INSTABILIDADE POLÍTICA}

A casuística em torno da modernização incompleta pode ser mais bem compreendida se colocarmos a questão da estabilidade/instabilidade política da América do Sul no contexto de seis clivagens que a seguir propõem-se e desenvolvemse.

\section{II.1. A renovação de elites e o Ascenso da} esquerda de várias tonalidades

Nesta primeira clivagem, os sistemas políticos sul-americanos têm assistido a uma circulação de elites que não é possível de explicar-se pelo aspecto geracional (quer dizer, pelo fato de tradicionais lideranças como Alfonsin na Argentina, Paz Estenssoro na Bolívia, Rafael Caldera na Venezuela, Leon Febres Cordeiro no Equador, entre outros, terem envelhecido), mas essa circulação de elites atenta para a reincidência de velhas insuficiências ou déficits político-institucionais e sociais que os regimes democráticos não conseguiram resolver ou que as experiências autoritárias agudizaram.

Esse fator de ordem tem sido responsável pela produção de uma série de lideranças que combinam uma tendência de esquerda moderada (Lula, Tabaré Vasquez e Michelle Bachelet) e alguns com uma forte tendência que mistura nacionalismo e esquerdismo, como no caso de Hugo Chávez, Evo Morales, Nestor Kirchner e outros que, mesmo não tendo obtido sucesso eleitoral, têm ganhado certa legitimidade política nas urnas, como os casos de Ollanta Umala no Peru e Manuel López Obrador no México.

Têm-se chamado várias dessas lideranças de neopopulistas Embora impreciso o termo, o neopopulismo vem sendo tentado a ser objeto de compreensão desde uma versão mais sofisticada e outra mais diletante. Na primeira dessas versões, Lodola (2004, p. 16), o neopopulismo mostra-se como um movimento compensador "aos perdedores na mudança econômica na América Latina”, e pode ser definido como um estilo estratégico de política caracterizado por uma agenda de cinco pontos: 1) um padrão de liderança personalizada não necessariamente carismática; 2) uma coalizão de apoio multiclassista; 3) uma forte mobilização social vertical ("de cima para baixo"); 4) uma ideologia eclética e anti-establishment; e 5) um uso sistemático de métodos redistributivos.

A segunda versão de neopopulismo é uma interpretação binária. Jorge Castañeda, em artigo publicado na Foreign Affairs no início de 2005, classificou a emergência de novas lideranças de esquerda na América Latina em um quadro tipológico binário, definindo o que chamou de a "esquerda radical e populista" e a "esquerda moderna” (CASTAÑEDA, 2006). 
No entanto, a continuidade das novas lideranças não pode ser reduzida a fórmulas binárias como a de Castañeda sobre a "esquerda certa" e a "esquerda errada” ou "ruim”. Essas fórmulas binárias não têm capacidade alguma de generalização e de explicação quando olhamos com mais cuidado o que tem acontecido com a história mais recente dos países sul-americanos. Essas categorias não podem explicar o que significa, para um venezuelano de classe média ou baixa, o imenso desprestígio dos partidos tradicionais na Venezuela ou na Bolívia. Também, essas fórmulas binárias não poderiam explicar o sucesso, manifesto na continuidade de um homem de direita que também poderia ser chamado de neopopulistas, como Álvaro Uribe na Colômbia.

\section{II.2. Política e identidades sociais e étnicas}

Uma segunda clivagem importante é pensar que a relação entre instabilidade e estabilidade política é afetada pela emergência de identidades sociais e étnicas entre algumas das novas lideranças e alguns setores sociais. Um elemento novo é que a identidade social e étnica chegou a ser congruente com a identidade política. Do ponto de vista da identidade social, parece estar emergindo, entre os setores socialmente excluídos, a percepção muito forte de que a "hora dos de baixo tem chegado". Casos como os de Chávez na Venezuela, Lula no Brasil ou de Evo Morales na Bolívia apontam para o fato de que setores sociais, geralmente os mais pobres, enxergam as novas lideranças por meio do prisma da identidade social, até minimizando a ausência de políticas públicas de maior alcance e aceitando aquelas de natureza assistencialista; a continuidade de administração patrimonial da máquina pública estatal; e as práticas de corrupção e comportamentos autoritários em algumas das novas lideranças.

No caso da Região Andina (Bolívia, Colômbia, Equador e Peru) manifesta-se também um forte componente étnico nas relações políticas que se estabelecem entre lideranças e setores sociais excluídos. Não é de se estranhar essa relação se levamos em conta que a Região Andina apresenta em sua composição étnica e demográfica um significativo número de indígenas, especialmente na Bolívia e no Equador, em que a percentagem desses na população é de $55 \%$ e $25 \%$, respectivamente. No Peru, pode ser considerada mestiça 45\% da população (VILLA, 2005).
Porém, um dado novo é que pode estar surgindo uma relação entre a forma como os setores indígenas percebem a representação política e as lideranças que elas concebem como seus representantes. O caso da Bolívia é exemplar para demonstrar o argumento. Desde 1978 os partidos indígenas (chamados de kataristas e indianistas) vinham a participar das disputas eleitorais, mas sem sucesso. Desde a conquista do direito de voto, na Revolução Nacionalista dos anos 50, o eleitor indígena boliviano tendia a votar freqüentemente no Movimento Nacional Revolucionário (MNR). "Isso foi possível porque o apoio eleitoral era aprovado na assembléia da comunidade indígena. Assim, no interior das comunidades o voto unânime era superior a $80 \%$ " (ARANDA, 2002, p. 85). Porém, nas eleições de 2002, os setores camponeses e indígenas, representados pelos líderes indígenas de esquerda, como Evo Morales e seu partido Movimiento al Socialismo (MAS), assim como pelo aimará de esquerda Felipe Quispe, do Movimiento Indígena Pachakuti, atingem uma representação de $31 \%$ no Congresso. E, nas eleições presidenciais de 2004, o MAS consegue eleger como Presidente da Bolívia o indígena aimará Evo Morales. No caso da Venezuela esse componente étnico também não está ausente. Mesmo no caso do Peru, a emergência de uma figura como Ollanta Umala revela uma tendência de identificação entre o político e o étnico.

Não seria exagerado afirmar que essa identificação entre o étnico e o político passa também pelo fato de que as demandas de legalidade de setores étnicos e sociais poderiam estar sendo mais bem traduzidas e mediadas pelas novas lideranças. Essa hipótese sustenta-se pelo fato de que, como detectado por pesquisa do Programa de Desenvolvimento das Nações Unidas para o Desenvolvimento, PNUD, sobre a "Democracia na América Latina”, os indígenas da Região Andina têm uma percepção bastante negativa sobre a igualdade legal. Esse é um percentual superior ao do México, um dos países latino-americanos de mais alta composição étnica indígena, em que apenas 7,5\% dos indígenas têm boa percepção a respeito da legalidade de seus direitos (PNUD, 2004a, p. 108).

Os setores indígenas vêm emergindo nos sistemas políticos e nas sociedades andinas, apresentando dois tipos de reivindicações básicas que acabam tencionando a governabilidade, dado 
que as elites tradicionais não criaram as condições, nem as instituições de bem-estar e de representação, necessárias para atender ambas as demandas: primeiro, "o reconhecimento constitucional [...] como sujeitos [de direito] no interior da nação” (ITURRALDE, 2001, p. 55); e segundo, a exigência de mudanças do marco político e legal, de modo a instituírem sua representação política nos âmbitos local e nacional. Essa segunda demanda implica que as reformas dos Estados andinos com forte presença indígena passam necessariamente pela inclusão das suas demandas por representação política.

\section{II.3. A equação polarização social e política}

Em decorrência da clivagem social, emerge também outra, de caráter político e social, em torno de novas lideranças. Essa clivagem decorre da polarização político-social oriunda da identificação do eleitor com o líder político a partir de semelhanças entre suas origens sociais. Chávez, Lula e Morales são exemplos.

As várias eleições venezuelanas realizadas desde 1998, as eleições presidenciais brasileiras de 2006 e as eleições presidenciais peruanas de 2006 tendem a reforçar a idéia de que os segmentos sociais mais pobres desses países tendem a votar em lideranças de origem mais popular. E os setores de maior renda em candidatos de origem social similar.

No caso do Brasil, a distribuição de votos nas eleições presidenciais de 2006 tende a confirmar a clivagem sócio-política quando relacionamos a distribuição dos votos dos dois candidatos que disputaram o segundo turno com o IDH municipal. "Nos 104 municípios do país com menor Índice de Desenvolvimento Humano (IDH), o candidato à reeleição para a Presidência, Luiz Inácio Lula da Silva (Partido dos Trabalhadores (PT)), recebeu o voto de praticamente três em cada quatro eleitores no primeiro turno. Lula teve 71,3\%, contra 24,35\% de Geraldo Alckmin (Partido da SocialDemocracia Brasileira (PSDB)). O total de eleitores nesses municípios é de 785 mil, sendo que 377 mil votaram em Lula e 129 mil em Alckmin. O tucano, por sua vez, obteve mais votos nos 104 municípios com maior IDH: 48,26\% contra 36,9\% de Lula. O número de eleitores nesse universo é bem maior: 26,9 milhões, dos quais 10,2 milhões votaram em Alckmin, e 7,8 milhões, em Lula" (ALCKMIN VENCEU NAS ÁREAS, 2006).

No caso do referendo presidencial venezuelano de agosto de 2004, alguns analistas, como Sierra, verificam que "Los resultados electorales evidencian como la identidad de clase operó como un elemento conformador de la llamada “polarización” política que se expresó simbólica y territorialmente en la ciudad de Caracas en la votación de aquellos” (SIERRA, 2005, p. 31).

A partir de dados oficiais, a autora mostra que o referendo tendeu a balizar claramente uma clivagem de classe, que se evidenciaria nos dados oficiais do quadro seguinte:

QUADRO 1 - DISTRIBUIÇÃO DOS VOTOS DO REFERENDO PRESIDENCIAL POR MUNICÍPIO

\begin{tabular}{|c|c|c|c|c|c|c|c|c|c|c|}
\hline \multirow{2}{*}{ MUNićpio } & \multicolumn{2}{|c|}{ ELEITORES } & \multicolumn{2}{|c|}{ WOTANTES } & \multicolumn{4}{|c|}{ OPÇôES } & \multirow[b]{2}{*}{ huLos } & \multirow{2}{*}{$\begin{array}{c}\text { ABSTENÇÕES } \\
\%\end{array}$} \\
\hline & $N$ & $\%$ & $N$ & $\%$ & "†มีคั & $\%$ & "SIMF" & $\%$ & & \\
\hline $\begin{array}{l}\text { LIEERTA- } \\
\text { DOR (D.C.) }\end{array}$ & 1331272 & 67 & 922210 & 69 & 516840 & 56 & 405360 & 44 & 10 & 31 \\
\hline SUCRE & 364227 & 18 & 249223 & 68 & 117441 & 47 & 131781 & 53 & 1 & 32 \\
\hline $\mathrm{CH} A \mathrm{CAO}$ & 72486 & 4 & 49864 & 69 & 9963 & 20 & 39901 & 80 & 0 & 31 \\
\hline BARUTA & 191717 & 10 & 143192 & 75 & 29513 & 21 & 113679 & 79 & 0 & 25 \\
\hline EL HATILLO & 38111 & 2 & 29544 & 78 & 5298 & 18 & 24246 & 82 & 0 & 22 \\
\hline TOTAL & 1997813 & 100 & 1394033 & 70 & 679055 & & 717967 & & 11 & 30 \\
\hline
\end{tabular}

FONTE: Sierra (2005, p. 31).

Enquanto no município de Libertador, em que se concentram os setores mais populares e mais numerosos de Caracas, houve uma tendência a votar a favor do "não” em relação à revogação do mandato presidencial (68\%) , nos municípios em que se concentra a maior parte da classe média e as frações de maior renda da cidade (Chacao, Baruta e El Hatillo) tendeu-se a se votar 
majoritariamente no "sim” (em uma proporção que foi de $79 \%$ a $82 \%$ ). O município de Sucre, que socialmente é um misto de setores populares e bairros de classe média, tendeu a confirmar a clivagem de classe no referendo, já que foi o município em que a votação foi a mais equilibrada: 53\% pelo "sim" e 47\% pelo "não" (ibidem).

Porém, se certamente a identidade social pode explicar a renovação de elites que decorre do surgimento e/ou consolidação de novas lideranças, não é uma inferência causal suficientemente convincente para explicar o voto de confiança dado às novas lideranças, que se expressam em sucessivas vitórias eleitorais para o legislativo e o executivo, como nos casos mais recentes do Brasil (reeleição do Lula), Venezuela (eleições parlamentares e para governador) e Colômbia (reeleição de Uribe). Nesses casos, a clivagem da polarização social tem sido acompanhada por iniciativas de políticas públicas que apresentam uma conjunção de elementos de curto prazo, na medida em que a maior parte delas tem se destinado a cobrir necessidades imediatas dos setores mais vulneráveis da população, com elementos de mais longo prazo.

A Venezuela de Chávez é talvez o caso exemplar. Embora as “misiones”, como são chamadas o conjunto de políticas públicas desenvolvidas desde 2003, tenham um forte caráter emergencial, algumas dessas políticas públicas, como as de saúde e educação (que conseguiram erradicar o analfabetismo no país) têm apresentado elementos de mais longo prazo. Da mesma forma, programas como bolsa escola, bolsa família e programas de geração de emprego e renda no Brasil têm conseguido promover uma redistribuição de renda, de tal forma que só no ano de 2004 a renda entre os mais pobres subiu mais de 14\% (FGV: REDISTRIBUIÇÃO FEZ RENDA, 2006)

Certamente, as relações entre estabilidade política (ou continuidade) e novas lideranças também têm origem na forma como algumas delas têm encarado o problema da violência política. Nos anos 1990, um populista autoritário como Alberto Fujimori conseguiu alavancar uma enorme popularidade no Peru com base no intenso combate ao grupo terrorista Sendero Luminoso. Nos anos 2000, na esteira do sucesso de Fujimori, Álvaro Uribe, na Colômbia, levou adiante sua particular cruzada contra os grupos guerrilheiros e narcotraficantes. A falta de recuperação econômica e o desborde de violência política no final do governo de Andrés Pastrana, na Colômbia, levaram ao poder Álvaro Uribe, considerado um político populista de direita. Uribe colocou-se com o objetivo de reunificar um país politicamente fragmentado e tomado pela violência de diferentes grupos políticos e não-políticos (guerrilhas, paramilitares e narcotraficantes). Uribe soube capitalizar os resultados de sua política de "segurança democrática" recebendo por isso um amplíssimo apoio da população colombiana, que enxergava o seu governo como o grande responsável pela recuperação da legitimidade de um Estado que até o ano de 2002 encontrava-se à beira do colapso. No trade-off de segurança por paz, a atitude da população colombiana, cansada de tantos anos de conflito, mostra sua disposição em ignorar os imensos custos políticos da solução de Uribe, que surgem como conseqüência dos excessos da aplicação de políticas repressivas de segurança interna que tendem a violar os direitos humanos de parte da população civil estabelecida nas zonas de conflitos entre exército e guerrilha (OSTOS, 2005; VILLA 2005).

Embora reconheça-se que falta uma investigação mais a fundo sobre esse tema, podemos tecer uma inferência inicial: as lideranças que têm surgido no campo de esquerda na América do Sul (seja qual for o qualificativo: modernas, populistas, nacionalistas etc.) seguem um padrão de atuação que tende a focalizar as políticas públicas de combate à desigualdade social como base sua legitimação política. Os casos de Lula, Kirchner, Chávez e Morales apontam nessa direção. As lideranças mais próximas do campo da direita, considerando os casos de Fujimori e Uribe, têm enfatizado o combate à violência política.

\section{II.4. O impacto das máquinas políticas tradicionais na percepção da democracia}

Uma quarta clivagem importante, da maior relevância, tem a ver, para parafrasear a Norberto Bobbio (1986), com o fato de que as promessas não cumpridas da democracia promoveram um desgaste imenso sobre as antigas máquinas partidárias que não conseguiram gerar respostas eficazes tanto às pressões que advinham dos déficits sociais gerados por décadas como às demandas geradas pela democratização; democratização esta que levou à incorporação de novos grupos sociais como os indígenas e/ou os movimentos organizados em torno de questões de saúde, moradia, terra e constitucionalização de 
novos direitos ao consumo e a um meio ambiente de qualidade. O resultado tem sido que os partidos políticos tradicionais foram enxergados pelas populações sul-americanas como responsáveis pelo crescente aumento da pobreza e da diminuição do bem-estar.

Os partidos políticos foram sem dúvida a instituição mais importante das elites políticas que governaram os países da região sul-americana nos últimos 50 anos. Desde o fim da década de 1990 assiste-se a um movimento quase generalizado de enfraquecimento das organizações políticas tradicionais e a aposta em novas lideranças: “À medida que a desaprovação dos partidos do status foi canalizada originalmente por forças 'políticas inovadoras', a estratégia destas últimas incorporava o sentimento de frustração do eleitorado que começava a sofrer o desengano da promessa democrática” (JIMÉNEZ, 2001, p. 68). Não por acaso, o Relatório sobre a Democracia na América Latina, do PNUD, aponta os partidos políticos como um dos atores que menos confiança suscita nas populações sul-americanas. Confirase o quadro a seguir.

QUADRO 2 - ÍNDICE DE CONFIANÇA EM INSTITUIÇÕES EATORES POLÍTICOS POR REGIÃO

\begin{tabular}{|c|c|c|c|c|c|c|c|c|c|}
\hline \multicolumn{6}{|c|}{ CONFIANÇA EM INSTITUÇÕES } & \multicolumn{4}{|c|}{ CONFIANÇA EM ATORES } \\
\hline Regẫo & $\begin{array}{l}\text { Poder } \\
\text { Judiciário }\end{array}$ & Governo & $\begin{array}{l}\text { Muni- } \\
\text { ćpios }\end{array}$ & $\begin{array}{l}\text { Congres- } \\
\text { so }\end{array}$ & Índice & $\begin{array}{l}\text { Gerte que } \\
\text { governa }\end{array}$ & $\begin{array}{l}\text { Patidos } \\
\text { políticos }\end{array}$ & Índice & $\begin{array}{l}\text { Índice de } \\
\text { confiança em } \\
\text { instituiçốese } \\
\text { aores }\end{array}$ \\
\hline $\begin{array}{l}\text { Certro- } \\
\text { Anérica e } \\
\text { México }\end{array}$ & 2,10 & 2,09 & 2,19 & 1,95 & 2,08 & 2,23 & 1,69 & 1,96 & 2,02 \\
\hline $\begin{array}{l}\text { Regẫo } \\
\text { Andina }\end{array}$ & 1,85 & 1,83 & 2,03 & 1,80 & 1,88 & 2,15 & 1,55 & 1,85 & 1,87 \\
\hline $\begin{array}{l}\text { Meroosule } \\
\text { Chile }\end{array}$ & 1,89 & 1,81 & 2,14 & 1,85 & 1,92 & 1,94 & 1,54 & 1,74 & 1,82 \\
\hline $\begin{array}{l}\text { América } \\
\text { Latina }\end{array}$ & $1, \infty 6$ & 1,93 & 2,12 & 1,88 & 1,97 & 2,12 & 1,61 & 1,86 & 1,91 \\
\hline
\end{tabular}

FONTE: PNUD (2004b).

Dada essa situação, por meio de um rápido balanço podemos constatar que partidos políticos tradicionais na América do Sul têm sofrido um forte desgaste em quase todos os países sul-americanos, com as exceções do Brasil e o Chile, sendo que o maior desgaste faz-se sentir na Região Andina. Na Venezuela, a ascensão de Hugo Chávez ao poder significou o enfraquecimento a níveis mínimos do espaço político dos dois partidos tradicionais, Acción Democrática e Copei, que num determinado momento chegaram a somar mais de $90 \%$ dos votos dos eleitores venezuelanos. $\mathrm{Na}$ Colômbia, os dois partidos tradicionais, o Partido Conservador e o Partido Liberal, consumiram-se em crises desde o fim da década de 90, que levou inclusive o Partido Liberal a dividir-se, dando origem à força política que elegeria Uribe em 2002. No Equador, o descontentamento social com partidos como a Democracia Cristã, a Esquerda Democrática e o Partido Social Cristão levou ao surgimento, em fins da década de 90, de partidos como o populista Sociedad Patriótica 21 de Enero, que levaria Lucio Gutierrez ao poder, ou de um partido representante dos setores indígenas como o Pachakuti - Nuevo País (MUPP-NP). Na Bolívia, partidos como o Movimento Nacional Revolucionário (MNR), fundado nos anos 1950 por Paz Estenssoro, perdeu muita força eleitoral na virada do século, surgindo novas forças como o Movimiento al Socialismo (MAS) de Evo Morales.

No Peru, o APRA (Alianza Popular Revolucionaria Americana), fundado nos anos 1920 do século passado por Victor Raul Halla de la Torre, que quase desapareceu nos anos 1990, teve uma nova oportunidade com a volta de Allan Garcia ao poder. No Uruguai, uma coalizão de esquerda, a Frente Ampla, liderada por Tabaré Vasquez, tem minado aos poucos as bases dos partidos tradicionais, o Colorado e o Branco, que governaram o país por mais de um século. E na Argentina, uma das forças políticas de maior histórico na América do Sul, o Partido Radical, é hoje em dia uma 
sombra política desde o rotundo fracasso do governo de Fernando de la Rua em 2001.

Mas o caso sul-americano continua a mostrar que partidos democráticos são indispensáveis para a democracia e o funcionamento de suas instituições. A ausência de partidos sólidos e de crenças e práticas democráticas no sentido forte tende a gerar vácuos políticos que, por sua vez, geram atores candidatos a cobrir tais vácuos despreparados para gerar práticas democráticas agregadoras de interesses sociais e políticos. Assim, pode-se gerar verdadeiras deformações dos objetivos e das instituições democráticas, e certamente em alguns casos esse processo resulta em instabilidade política. A situação de turbulência política vivida pela Venezuela entre 2002 e 2004 e pelo Equador entre 1997 e 2005 são claros exemplos de países em que o antigo sistema partidário, uma vez desestruturado ou minado, não foi substituído por outro sistema de partidos com objetivos democráticos claros. Assim, em ambos os países os candidatos a substituir ao antigo sistema de partidos variaram de um leque que inclui frentes políticas heterogêneas como a V Republica de Hugo Chávez na Venezuela, a Sociedad Patriótica 21 de Enero de Lucio Gutierrez. O que é mais significativo, no caso venezuelano, é que setores da mídia, dos empresários e de algumas organizações não-governamentais (ONGs) transformaramse em atores políticos não só usurpando um papel de representação (e de oposição) que não lhes correspondia e para o qual não estavam preparados, mas transformando-se também em fatores de instabilidade política. Quando isso acontece, as instituições democráticas são instrumentalizadas por bandos geralmente polarizados, não sendo a democracia um objetivo visto como prioritário.

Um resultado concreto do que Bobbio chama de as "promessas não cumpridas da democracia”, que se relaciona com o baixo rendimento institucional de partidos e outras instituições como o parlamento, é que se tem alimentado certo sentimento ambivalente quanto ao apoio à democracia e seus efeitos, e sua capacidade para promover meios de representação eficazes que promovam políticas sociais de inclusão. É aceitável o argumento de que as populações latino-americanas não reagem contra a democracia, mas contra a forma como suas instituições têm funcionado (COUTINHO, 2006): o Relatório sobre a Democracia na América Latina, do PNUD (2004a), tende a detectar esse crescimento de sentimentos ambivalentes quanto ao apoio à democracia: "Em 2002 os democratas pertenciam à tendência mais difundida entre os latino-americanos, não chegando, porém, a formar uma maioria [...]. Somaram 43\% dos consultados nos dezoito paises da América Latina. Entretanto, o apoio majoritário à democracia depende dos ambivalentes, que são a segunda tendência mais difundida (30,5\%). Finalmente, os não democratas pertenciam à tendência menos difundida: $26,5 \%$ por cento dos consultados" (idem, p. 142). Como questiona Coutinho: "Teoricamente, o populismo prospera onde o institucionalismo periférico não consegue alcançar, o que não significa dizer que um seja menos democrático que o outro. Na realidade, os eleitores podem enxergar em líderes mais carismáticos uma saída para o desenvolvimento quando as regras e organizações democráticas tradicionais não realizam bem o seu papel social. Sendo assim, a desconfiança da população não é com a democracia propriamente dita, mas com o que ela tem gerado em termos práticos, tendo em vista um discurso alienado por parte do institucionalismo" (COUTINHO, 2006, p. 121).

Ao certo não se pode inferir que exista uma correlação positiva entre algumas crises institucionais recentes e percepções e atitudes em relação à democracia, mas dados do mesmo relatório do PNUD apontam que a América do Sul é a região em que a distância entre democratas e ambivalentes é mais curta do que entre democratas e não-democratas. "Na América Central e no México, os democratas são quase a metade da população, representam mais do que o dobro dos não-democratas e têm ampla vantagem sobre os ambivalentes. Nos países do Mercosul e do Chile há uma situação polarizada: as tendências mais difundidas são as opostas: os democratas e os nãodemocratas; além disso a diferença de magnitude entre ambos é estreita. Finalmente, na Região Andina existe um equilíbrio entre as três tendências: a diferença entre os democratas e os ambivalentes é pequena, e nenhuma consegue uma vantagem ampla sobre os não-democratas" (PNUD, 2004a, p. 142).

Deve somar-se a isso o fato de que alguns desdobramentos políticos vêm mostrando também uma incongruência entre escolhas de políticas econômicas e eficiência institucional democrática. Isto é, indicadores macroeconômicos têm bom rendimento enquanto que indicadores políticos demonstram um baixo rendimento. Isso leva à 
questão de que possivelmente tem havido uma incongruência entre eficiência neoliberal e desenvolvimento institucional. Um exemplo disso foi a chegada ao poder, no Peru, de Alejandro Toledo, um liberal convicto. Em 2002, o déficit fiscal foi de 2,2\% em relação ao PIB, e a inflação 1,5\%. Em 2003, o crescimento do PIB peruano foi de $4 \%$, o maior da região, e a inflação 2,5\% (CAN, 2004a; 2004b). Também, os indicadores da Comunidade Andina de Nações (CAN) mostram que o desemprego foi o menor da região em 2003. No entanto, o índice de aprovação do Presidente Toledo caiu de 59\%, em agosto de 2001, para 14\% em outubro de 2002 (ICG, 2003, p. 23). De igual no Semelhante é o caso do Equador, em que o índice de preços ao consumidor, que em 2001 chegou a estar em $90 \%$ ao ano, caiu para $2 \%$ em 2004. No entanto, a instabilidade política da figura presidencial foi uma das características do país entre 2000 e 2005. Claro está que no caso da Argentina a crise que se instalou nas instituições em
2003 também tem como origem a forma negativa em que indicadores macroeconômicos como a estabilidade monetária e inflacionária viram-se afetados desde fins da década passada.

É possível levantar a hipótese de que, em parte, tal discrepância ocorre pelo fato de que, para parte das populações sul-americanas, já não é mais vantagem suportar os ônus do bem-estar social que decorre das escolhas macroeconômicas liberais, que em determinado momento foram bem justificadas pelas elites políticas como escolhas feitas devido à exigência de estabilidade de metas macroeconômicas do momento, principalmente controle da inflação, estabilidade monetária e rigidez fiscal. Não é improvável que esse discurso tenha atingido um nível de saturação, posto que indicadores de bem-estar como o aumento da renda per capita e o desemprego pouco tenha diminuído, enquanto que a pobreza e a indigência incrementaram-se, como mostram os quadros 3 , 4 e 5 logo a seguir.

QUADRO 3 - INDICADORES DA SUB-REGIÃO ANDINA

\begin{tabular}{|l|l|l|l|l|l|l|l|}
\hline & $\begin{array}{l}\text { Índice de } \\
\text { Reforma } \\
\text { Econômi- } \\
\text { ca }\end{array}$ & $\begin{array}{l}\text { Índice de } \\
\text { Democra } \\
\text { cia } \\
\text { Eleitoral }\end{array}$ & $\begin{array}{l}\text { Crescimen- } \\
\text { to do PIB } \\
\text { real per } \\
\text { capita (\%) }\end{array}$ & $\begin{array}{l}\text { Pobreza } \\
\text { (\%) }\end{array}$ & $\begin{array}{l}\text { Indigên- } \\
\text { cia (\%\%) }\end{array}$ & $\begin{array}{l}\text { Coeficien- } \\
\text { te de Gini }\end{array}$ & $\begin{array}{l}\text { Desempre- } \\
\text { go Unbano }\end{array}$ \\
\hline $1982-90$ & 0,53 & 0,83 & $-0,6$ & 52,3 & 22,1 & 0,497 & 8,8 \\
$1992-97$ & 0,76 & 0,86 & 0,9 & 50,4 & 18,1 & 0,544 & 8,3 \\
$1998-02$ & 0,82 & 0,83 & 0,1 & 52,7 & 25,0 & 0,545 & 12,0 \\
\hline
\end{tabular}

FONTE: PNUD (2004a).

QUADRO 4 - INDICADORES DA REGIÃO DO CONE SUL

\begin{tabular}{|c|c|c|c|c|c|c|c|}
\hline & $\begin{array}{l}\text { Índice de } \\
\text { Reforma } \\
\text { Econô- } \\
\text { mica }\end{array}$ & \begin{tabular}{|l} 
Índice de \\
Democra- \\
cia \\
Eleitoral
\end{tabular} & 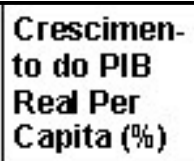 & $\begin{array}{l}\text { Pobreza } \\
\text { (听) }\end{array}$ & $\begin{array}{l}\text { Indigência } \\
\text { (晿) }\end{array}$ & $\begin{array}{l}\text { Coeficien- } \\
\text { te de Gini }\end{array}$ & $\begin{array}{l}\text { Desemprego } \\
\text { Ubano }\end{array}$ \\
\hline $1982-90$ & 0,66 & 0,44 & $-0,8$ & 25,6 & 7,1 & 0,502 & 8,8 \\
\hline $1992-97$ & 0,82 & 0,88 & 1,3 & 21,2 & 5,7 & 0,527 & 8,7 \\
\hline 1998-02 & 0,84 & 0,91 & 1,0 & 32,3 & 12,9 & 0,558 & 12,1 \\
\hline
\end{tabular}

FONTE: PNUD (2004a).

QUADRO 5 - INDICADORES DO BRASIL

\begin{tabular}{|l|l|l|l|l|l|l|l|}
\hline & $\begin{array}{l}\text { Índice de } \\
\text { Reforma } \\
\text { Econô- } \\
\text { mica }\end{array}$ & $\begin{array}{l}\text { Índice de } \\
\text { Democra- } \\
\text { cia } \\
\text { Eleitoral }\end{array}$ & $\begin{array}{l}\text { Crescimen- } \\
\text { to do PIB } \\
\text { Real Per } \\
\text { Capita (\%) }\end{array}$ & $\begin{array}{l}\text { Pobreza } \\
(\%)\end{array}$ & $\begin{array}{l}\text { Indigência } \\
\text { (\%) }\end{array}$ & $\begin{array}{l}\text { Coeficien- } \\
\text { te de G ini }\end{array}$ & $\begin{array}{l}\text { Desempre- } \\
\text { go Urbano }\end{array}$ \\
\hline $1982-90$ & 0,52 & 0,70 & 1,7 & 48,0 & 23,4 & 0,603 & 5,2 \\
$1992-97$ & 0,75 & 1,00 & 0,4 & 40,6 & 17,1 & 0,638 & 5,3 \\
$1998-02$ & 0,79 & 1,00 & 1,1 & 37,5 & 13,1 & 0,640 & 7,1 \\
\hline
\end{tabular}


A discrepância entre política e economia é confirmada pelas informações constadas no relatório do PNUD sobre a democracia na América Latina. Dados quantitativos apresentados pelo relatório mostram que os índices de desempenho das reformas econômicas sofreram uma freada desde finais da década de 1990, enquanto que os índices de reformas eleitorais melhoraram. Quanto às reformas econômicas, na Região Andina, no período de 1992-1997 o índice foi de 0,76, e subiu para 0,82 no período 1998-2002. Já as reformas políticas eleitorais (medidas pelo índice de democracia eleitoral) passaram de 0,86 no período de 1992-1997 para 0,83 no período 1998-2002 (PNUD, 2004a). No Cone Sul (Argentina, Chile, Paraguai e Uruguai), no período de 1992-1997, as reformas econômicas atingiram um índice de 0,82 , e as reformas eleitorais de 0,88 . No período 1998-2002, as reformas econômicas atingiram um limite de 0,84 e o índice de democracia eleitoral de 0,91 . O Brasil foi o único país da região sulamericana que atingiu um crescimento lento das reformas econômicas no período de 1992 a 1997 enquanto atingia um índice quase perfeito de 1,0 quanto às reformas eleitorais (idem).

Na verdade, as reformas econômicas liberais aplicadas nos anos 90 na Região Sul-americana como um todo não puderam resolver os problemas estruturais mais sérios da região. Nos dados apresentados no estudo do PNUD, mostra-se claramente que a desigualdade diminuiu pouco ou nada na região: o Índice de Gini (média de desigualdade ponderada por população) é alarmante nesse sentido. No período 1991-1998 o coeficiente que era de 0,544, já no período 1998-2002 subiu para 0,5465 . Isso significa que a Região Andina está mais pobre e mais desigual do que há 15 anos atrás, já que no período 1982-1990 o Índice se localizava em 0,497. O mesmo pode-se dizer da Região Cone Sul: enquanto que no período de 1981-1990 o Gini atingia uma média de 0,502, no período de 1998 a 2002 atingiu 0,558. No caso do Brasil, ao comparar ambos os períodos, também se observa uma elevação do índice. Em outras palavras, a Região Sul-americana ingressava no século XXI mais pobre do que há uma década.

A isso devemos acrescentar que, no período 1991-1998, 18,2\% da população vivia na pobreza nos países andinos e 8,3\% da população economicamente ativa estava desempregada. Já no período de 1998-2002, 25\% da população vivia na pobreza e $12 \%$ desempregada. Em outras palavras, se não existe coincidência entre o relativo sucesso das reformas e o funcionamento das instituições, talvez possamos adiantar a hipótese de que existe mais proximidade entre as falhas estruturais socioeconômicas e baixo rendimento das instituições políticas, o que leva a crer que em certas circunstâncias esse baixo rendimento institucional expresse-se em crises institucionais, algumas delas pressionadas pela força que adquiriram os novos movimentos sociais (cf. VILLA, 2005).

II.5. Novos atores sociais e políticos entram em cena

Uma quinta clivagem dá-se pelo fato de que novos setores sociais entram em cena em busca de representação política. Os mais expressivos desses novos setores sociais têm ganhado forma política em novos movimentos sociais organizados, chamados de piqueteiros na Argentina, sem terras ou sem tetos no Brasil, “cocaleiros” na Bolívia, círculos bolivarianos na Venezuela e movimento indígena em lugares como Equador, Peru e Bolívia (ou se quisermos ir mais longe movimentos de produtores organizados no caso mais recente do México).

Em princípio, poder-se-ia pensar que as novas lideranças às quais se classifica como neopopulistas, por exemplo, os casos de Evo Morales na Bolívia, Ollanta Umala no Peru e López Obrador no México, tem-se aproveitado de "massas em disposição" e que tais lideranças têm sido suficientemente hábeis e sensíveis para incorporar às suas plataformas políticas e aos seus discursos as demandas desses setores sociais como uma forma de fornecer maior legitimidade a seu discurso político.

Esse fato poderia até sugerir certa instrumentalidade de esses setores sociais. Mas seria errôneo pensar que são só "massas em disponibilidade" - como a emergência das massas foram chamadas, na política brasileira na transição da sociedade tradicional para a moderna, no importante trabalho de Weffort (1989) - o que encontram essas novas lideranças em seu caminho ao poder. Ao contrário dos populismos do passado, como os de Getúlio Vargas ou Perón, as massas que os chamados neopopulistas encontram dispõem de certo grau de organização e de autonomia de objetivos. Como resultante, ainda que alguns dos movimentos sociais identifiquem- 
se a princípio com as metas das novas lideranças, também é certo que o apoio posterior dos primeiros (dos movimentos sociais) fica condicionado ao desenvolvimento de políticas públicas de inclusão.

O efeito mais profundo dessa "barganha” é que a instabilidade política torna-se uma espécie de fantasma que ronda os sistemas políticos sul-americanos desde a década de 90. É necessário esclarecer esse ponto. O surgimento e incorporação desses setores sociais têm resultado num ganho substantivo muito importante para o desenvolvimento e aprofundamento democrático na América do Sul. Novas poliarquias democráticas surgiram pluralizando a esfera pública da decisão e criando pressões para os tomadores de decisão com relação à democratização dos espaços estatais de decisão. E o que é mais significativo, com o surgimento desse tipo de movimento orgânico geraram-se pressões de inclusão política (representação política de alguns grupos sociais como negros, mulheres e indígenas), social (luta pela diminuição das desigualdades de renda) e legal (constitucionalização de direitos, como no caso dos indígenas andinos). Todas essas pressões, hoje politicamente organizadas, tem sido um dos acontecimentos mais positivos a que tem assistido a política sul-americana nos últimos dez anos.

Não se poderia sugerir, em momento algum, que esses novos segmentos organizados sejam de por si um fator de instabilidade política. Porém, o fato de contar com um grau de organicidade política que estava ausente nas velhas experiências populistas faz que as promessas não cumpridas das lideranças que estão no poder tenham muita margem para o esquecimento em nossos dias. $\mathrm{Ou}$ que decisões enxergadas como antipopulares, negadoras da soberania nacional ou de manutenção do status quo de grupos privilegiados, tenham menos margem para a aceitação passiva. De alguma maneira, o desenvolvimento da democracia contribui para o fortalecimento de uma forma de accountability vertical ${ }^{1}$ que tem como protagonistas esses novos setores sociais organizados.

Diferente do passado em que as "massas em disponibilidade" eram um fato real, e dessas "massas em disponibilidade" de que se valia o populismo clássico do estilo de Vargas e Perón, as novas li-

\footnotetext{
$\overline{1}$ Essa categoria foi desenvolvida por O’Donell (1998).
}

deranças já ascendem ao poder como um setor social mais orgânico. O deposto Lucio Gutierrez, no Equador, por exemplo, chegou ao poder em aliança com um setor indígena que vinha organizando-se fortemente desde a década de 1990. Mas foi o mesmo setor indígena que contribui para tirar Gutierrez do poder. Também Carlos Meza, sucessor de Gonzalo Sanchez de Lozada, na Bolívia, deve sua saída do poder ao fato de que suas políticas de recursos energéticos não atendiam aos interesses tidos como soberanos por grupos sociais no país. Não por acaso na campanha presidencial de 2005, todos os candidatos, desde os setores mais à esquerda até os setores tidos como mais conservadores, colocavam como meta prioritária a nacionalização do gás e o petróleo na Bolívia. E Fernando de la Rua, em 2001, deve em parte sua saída do poder na Argentina ao fato de que movimentos sociais, como "os piqueteiros", não estavam mais dispostos a aceitar medidas consideradas antipopulares e que eram percebidas por esses setores como impostas verticalmente por organismos internacionais.

\section{CONCLUSÕES}

Em termos gerais, América do Sul tem apresentado uma mistura de estabilidade e instabilidade política. Mas, certamente, em lugares como a Região Andina, a instabilidade política que a abateu na década de 1990 e início da de 2000 pode ser explicada como uma crise de legitimidade de seus sistemas políticos. De acordo com Adrián Bonilla, "Desde meados dos anos 1990 todos os Estados da Região Andina têm vivido permanentes crises políticas definidas por uma legitimidade precária, produto de um déficit crônico de representação. Este déficit teria ao menos três características: a) a maior parte das pessoas não participam nos processos de tomada de decisões estratégicas nacionais, e tampouco naqueles que se referem a assuntos particulares de suas comunidades; b) não existem mecanismos eficientes de prestação de contas. Os níveis de impunidade, tanto na sociedade civil quanto no exercício do poder político, são extremamente altos; e c) uma parte importante da sociedade carece da cidadania” (BONILLA, 2001, p. 173). Porém, a crise de legitimidade expressa-se também na crise de instituições de mediação de interesses societais, especialmente os partidos políticos, responsabilizados diretamente pelas populações nacionais como os culpados pela ausência de um Estado de bemestar social universal aos cidadãos. É nesse vá- 
cuo de legitimidade que tem emergido lideranças que vêm sendo chamadas de neopopulistas.

Também é certo que na região do Mercosul mais o Chile, a existência de partidos políticos, e até de transições democráticas pactuadas, como no caso de Chile, tem conseguido fazer que as pressões dos grupos sociais e políticos sejam agregadas e canalizadas institucionalmente, embora em determinados momentos, como no caso da Argentina de inícios dos anos 2000, a pressão social chegou a ser tão forte que os partidos políticos pouco puderam fazer para evitar a instabilidade política que se materializou na troca de vários presidentes em poucas semanas.

Mas faz-se necessário também atentar, por outro lado, às relações causais que têm sido estabelecidas entre a instabilidade política e as lideranças chamadas de neopopulistas. É até possível admitir elementos de causalidade do neopopulismo em relação à instabilidade política, como no caso da Região Andina, porém o conceito de neopopulismo talvez ressinta de um tratamento histórico mais rigoroso. Além do uso ideologizado com que às vezes aplica-se o termo a algumas das novas lideranças, o conceito pode não recolher tendências retroativas de longo pra- zo que já se manifestavam antes da emergência da figura tida como populista, que tencionam a percepção e conceituação de estrangeiros que recaem sobre essas figuras (VILLA \& URQUIDI, 2006). O conceito é acometido por uma falta de historicidade. O histórico das personalidades é ignorado ou subestimado, relegando-os a um vácuo histórico, como se fossem os únicos responsáveis pelas características do regime. Em primeiro lugar, porque perde-se de vista o contexto histórico em que a personalidade surge e, em segundo lugar, a sua própria história política. A emergência da figura de Chávez, por exemplo, não pode ser desvinculada da crise dos partidos tradicionais ou dos déficits sociais gerados pela modernização incompleta. Um segundo aspecto que o conceito de neopopulismo não consegue refletir de maneira adequada refere-se ao aspecto da legitimidade. Alguns dos governantes que entram na categoria de neopopulistas têm em comum o fato de terem sido expressão da vontade política de maiorias significativas de suas populações nacionais. Cabe então finalizar com uma questão: essas dificuldades em entender a mudança política não estão sugerindo, então, que a mudança política e social tem sido acompanhada pela mudança conceitual nas ciências sociais sul-americanas?

Rafael Duarte Villa (rafaelvi@usp.br) é Doutor em Ciência Política pela Universidade de São Paulo (USP) e professor de Ciência Política na mesma instituição.

\section{REFERÊNCIAS BIBLIOGRÁFICAS:}

ARANDA, A. 2002. A questão étnica e cultural na política boliviana no cenário do pós-Guerra Fria. São Paulo. Tese (Doutorado em Ciência Política). Universidade de São Paulo.

BOBBIO, N. 1986. O futuro da democracia : uma defesa das regras do jogo. São Paulo : Paz e Terra.

BONILLA, A. 2001. Vulnerabilidad internacional y fragilidad doméstica : la crisis andina en perspectiva regional. Nueva Sociedad, Caracas, n. 51, may-jun. Disponível em : http:// www.nuso.org/upload/articulos/2965_1.pdf. Acesso em : 22.jan.2009.

CAN. 2004a. Indicadores económicos de la Comunidad Andina, Mercosur y Chile. Quito : Comunidad Andina de Naciones. 2004b. Indicadores económicos de la Comunidad Andina, 1999-2003. Quito : Comunidad Andina de Naciones.

CASTAÑEDA, C. 2006. Latin America's Left Turn. Foreign Affairs, n. 85, May-June. Disponível em : http://www.foreignaffairs.org/ 20060501faessay85302/jorge-g-castaneda/ latin-america-s-left-turn.html. Acesso em : 22.jan.2009.

COUTINHO, M. 2006. Movimentos de mudança política na América do Sul contemporânea. Revista de Sociologia e Política, Curitiba, n. 27, p. 107-123, nov. Disponível em : http:// www.scielo.br/pdf/rsocp/n27/08.pdf. Acesso em : 13.jan.2009. 
ICG. 2003. Colômbia e seus vizinhos : os tentáculos da instabilidade. Relatório sobre a América Latina. Bogotá : International Crisis Group.

ITURRALDE, D. 2001. Pueblos andinos en América Latina y reformas neoliberales. Anuário Social y político de América Latina y el Caribe, Caracas, n. 4.

JIMÉNEZ, A. R. 2001. Partidos y sistemas de partidos en las democracias andinas. Nueva Sociedad, Caracas, n. 51, mayo-jun. Disponível em : http://www.saber.ula.ve/bitstream/ 123456789/15734/1/sistemas_partidos.pdf. Acesso em : 22.jan.2009.

LODOLA, G. 2004. Neopopulismo y compensaciones a los perdedores del cambio económico en América Latina. Diálogo Político, Buenos Aires, n. 92, mar.

O’DONELL, G. 1998. Accountability horizontal e novas poliarquias. Lua Nova, São Paulo, n. 44 , p. $27-54$

PNUD. 2004a. A democracia na América Latina. Rumo a uma democracia de cidadãs e cidadãos. São Paulo : Programa da Organização das Nações Unidas para o Desenvolvimento. 2004b. La democracia en América Latina. Anexo estadístico. Buenos Aires : Programa de la Organización de las Naciones Unidas para el Desarrollo.

SIERRA, R. 2006. Tensiones y conflictos entre las ciudades que se globalizan y los Estados Nacionales. Estudio de caso de Caracas. Digit.

VILLA, R. D. 2005. Los países andinos : tensiones entre realidades domésticas y exigencias externas. In : DUPAS, G. (org.). América Latina a comienzos del siglo XXI. Perspectivas económicas, sociales y políticas. Rosário, Argentina : Homo Sapiens.

VILLA, R. D. \& OSTOS, M. P. 2005. As relações entre Colômbia, países andinos e Estados Unidos : visões em torno da agenda de segurança. Revista Brasileira de Política Internacional, Brasília, v. 48, n. 2, p. 86-110. Disponível em : http://www.scielo.br/pdf/rbpi/ v48n2/a05v48n2.pdf. Acesso em : 22.jan.2009.

VILLA, R. D. \& URQUIDI, V. D. 2006 Venezuela e Bolívia : legitimidade, petróleo e neopopulismo. Política Externa, São Paulo, v. 14, n. 4, p. 63-78.

WEFFORT, F. 1989. O populismo na política brasileira. São Paulo : Paz e Terra.

\section{OUTRAS FONTES}

Alckmin venceu nas áreas com maior desenvolvimento humano; Lula, nas de menor. 2006. Notícias Terra, 12.out., seção “Eleições 2006”. Disponível em : http://noticias.terra.com.br/ eleicoes2006/interna/0, OI1188143EI6652,00.html. Acesso em 13.jan.2009.
FGV : redistribuição fez renda de pobres crescer 14\%. 2006. O Globo, Rio de Janeiro, 9.jun., caderno "Economia", p. 35. Disponível em : http://www4.fgv.br/cps/simulador/impacto_2006/ic239.pdf. Acesso em : 13.jan.2009. 
VERS UNE THÉORIE AU-DELÀ DE L’ÉTAT: LA DOUBLE DÉMARCHE DE DÉNATURALISATION ET TEMPORALISATION

\section{Diego Santos Vieira de Jesus}

L'article a pour objectif non seulement d'expliquer pourquoi une double démarche de dénaturalisation et temporalisation favorise un premier pas vers une théorie envisageant la dissolution des notions d'autorité et d'identité du concept d'État et la redéfinition du problème de l'ordre politique international, mais encore d'identifier, dans les débats récents de la théorie politique et de la théorie de Relations Internationales, des approches alternatives allant vers cette double démarche. L'hypothèse centrale dont la justesse on envisage de vérifier est que la double démarche de dénaturalisation et temporalisation permet l'affaiblissement en simultanée des segments internes qui confortent l'État et qui le distinguent comme locus d'autoritié opposé à des forces apolitiques de la société domestique et des divisions externes qui le différencient des organisations internationales similaires. A partir de ce manque de stabilité, on met en question les interprétations étatiques de l'autorité et on redéfinit les débats sur l'ordre politique international, tout en générant de nouvelles matrices et en renouvelant l'entendement du politique : non seulement des organisations alternatives de l'espace peuvent être considérées à partir de l'appréciation de la différence comme moyen d'auto-reflexion et de critique sociale, mais aussi on peut admettre des perpectives envisageant des incohérences et ambigüités des pratiques étatiques et mettant en question le contrôle de l’État sur des espaces et des corps à la recherche de préservation de leur statut ontologique et pratique.

MOTS-CLÉS : Théorie Politique ; théorie des Relations Internationales ; théorie post-moderne ; État ; dénaturalisation ; temporalisation.

NOUVEAUX LEADERS SUD-AMÉRICAINS: CLIVAGE SUR LE BINÔME STABILITÉINSTABILITÉ POLITIQUE

\section{Rafael Duarte Villa}

L'article traite de l’instabilité politique en Amérique latine, surtout au Brésil et dans les pays composant la Région Andine et le Cône Sud. Nous étudions les causes de l'apparition des nouveaux leaders politiques dans ces pays et leur rapport aux situations de stabilité ou d'instabilité politiques. L'article défend que l'avènement de nouveaux leaders en Amérique latine, qui ont émergé dans un contexte de stabilité et instabilité politique, ne peut être compris seulement par des hypothèses mettant en relief les caractéristiques populaires ou les défaillances de la modernisation politique, vu que la casuistique plus profonde de cette émergence devrait être cherchée dans de nouveaux clivages d'identité éthnique et sociale ainsi que d'un nouveau modèle de rapport entre mouvements sociaux et nouveaux leaders. Nous concluons que l'ascension des nouveaux leaders politiques dans les pays analysés est souvent liée à une crise de légitimité du système politique. Nous assumons aussi que le « néo-populisme » peut être une variable explicative de l'émergence de nouveaux acteurs dans des contextes d'instabilité politique, à condition que cette variable ne soit pas descontextualisée.

MOTS-CLÉS : élite politique ; néo-populisme ; Région Andine ; instabilité politique ; légitimité politique ; économicisme. 
TOWARD THEORIZING BEYOND THE STATE: THE TWO-FOLD PROCEDURE OF DENATURALIZATION AND PROVIDING TEMPORALITY

\section{Diego Santos Vieira de Jesus}

This purpose of this article is to explain why a two fold procedure of denaturalization and providing temporality offers the first step toward a new type of theorizing. We refer to the dissolution of notions of authority and identity of the State and the re-definition of the problem of the international political order, as well as identifying alternative approaches that pursue the course offered by this two-fold procedure within recent debates on political theory and theories of international relations. The central hypothesis whose correctness we intend to verify here is that this twofold procedure of denaturalization and providing temporality (time-boundedness) allows the simultaneous destabilization of the internal segments that strengthen the State and differentiate it as a locus of authority counterposed to apolitical forces of domestic society and of the external divisions that distinguish it from similar international entities. Through this destabilization, Statist interpretations of authority are problematized and discussions on the international political order are re-defined, creating new matrixes and renewing our understanding of the political. Alternative forms of organizing space can thereby be thought up, on the basis of appreciation of difference as a means for self-reflection and social critique, and perspectives that consider the inconsistencies and ambivalence of State practices and that question State control over spaces and bodies, in favor of the preservation of their ontological and practical status, can be developed.

KEYWORDS: Political Theory; International Relations Theory; Post-modern Theory; State; denaturalization; temporalization.

\section{NEW SOUTH AMERICAN LEADERSHIP: CLEAVAGES IN THE STABILITY-INSTABILITY} BINOMY

Rafael Duarte Villa

This article looks at political instability in Latin America, particularly for the countries that make up the Andean region, the Southern Cone and Brazil. We inquire into the causes behind the emergence of new political leadership in these countries and the relationship that such leadership has with situations of political stability or instability. We sustain that the emergence of new leadership in Latin America, which has emerged within a dynamic of political stability and instability cannot be understood solely through hypotheses that give salience to populist traits or flaws in processes of political modernization. Rather, deeper causal explanation for the appearance of such new leadership should be sought in the new cleavages that demonstrate the renovation of elite groups, as well as the emergence of ethnic and social divisions and of new patterns of relationship between social movements and new leadership. We conclude that the rise of new political leadership in the countries that we analyze is generally linked to a legitimacy crisis within the political system. We also hold that "neo-populism" may be an explanatory variable for the emergence of new actors in contexts of political instability, but care must be taken to give adequate emphasis to contextual factors.

KEYWORDS: political elite; neo-populism; Andean region; political instability; political legitimacy; economicism. 